\title{
Smart Agriculture Using IOT
}

\author{
${ }^{1}$ Sarang Nagpure, ${ }^{2}$ Sadashiv Ingale, ${ }^{3}$ Sameer Pahurkar, ${ }^{4}$ Ankur M Bobade, ${ }^{5}$ Munmun Ghosal, ${ }^{6}$ Tanuja \\ Dhope \\ ${ }^{1-3}$ B.E (E\&TC), GHRCEM, Pune, India \\ ${ }^{4-6}$ Department of E\&TC, GHRCEM, Pune, India \\ Email: sarang434@gmail.com,smrpahurkar@gmail.com, sadashivingale7@gmail.com, \\ ankurmbobade@gmail.com,munmun55@gmail.comranuja.dhope@raisoni.net
}

Received: $17^{\text {th }}$ January 2019, Accepted: $13^{\text {th }}$ February 2019, Published: $30^{\text {th }}$ June $_{2019}$

\begin{abstract}
Agriculture adds to a noteworthy segment of India's Gross domestic product. Two noteworthy issues in present day agriculture are water shortage, scheduling and animals attacks on crops. These issues can be settled utilizing agriculture undertaking mechanization, which energizes exactness agriculture. Considering wealth of daylight in India, this project talks about the outline and advancement of an IOT based Smart Agriculture that atomizes water system errand and empowers remote ranch checking. The smart agriculture is produced utilizing an Arduino microcontroller. While executing the assignment of water system, it checks soil and temperature parameters, and faculties' soil dampness substance and temperature at general focuses. At each detecting point, information procured from numerous sensors is handled locally to choose the need of water system and in like manner cultivate is watered. On the other hand we will use a smart compound to our farm consisting current pulses which will keep animals away from farm and crop harming is avoided. Further, smart agriculture goes about as an IOT gadget and transmits the information gathered from different sensors to a remote server Android App utilizing Wi-Fi connects. At the remote server, crude information is handled utilizing signal preparing activities such as filtering, pressure and forecast
\end{abstract}

Keywords

IOT, WIFI Module, Irrigation, Farm Monitoring

\section{Introduction}

The quality of Indian's financial system is farming. In any case, for farming water utilization is more than precipitation consistently. Enhancing ranch yield is fundamental to take care of the quickly developing demand of sustenance for populace development over the world. By considering and foreseeing natural conditions, cultivate efficiency can be expanded. Product quality depends on information gathered from field, for example, soil dampness, surrounding temperature and stickiness and so on. Propelled instruments and innovation can be utilized to build cultivate yield. Creating IOT advances can gather expansive measure of biological and product presentation information. "IOT incorporates numerous new canny ideas for utilizing as a part of the not so distant future, for example, brilliant home, keen city, savvy transportation, and shrewd cultivating". The method can be utilized for utilization of exact measure of compost, water, pesticide and so on to upgrade profitability and greatness. Sensors are confident gadget for keen agriculture. The constant ecological strict urea kin to soil dampness intensity, surrounding temperature \& container water altitude contain nonstop effect on product lifecycle. Via framing sensor arrange, great checking of water direction in the farming can be accomplished. The irrigation monitoring and controlling system is presented by this document. The system exploit WSN to observe the ecological situation like humidity, moisture content in soil, temperature and Soil water altitude of agriculture land for calculating the irrigation and advanced farm compounds is also used to avoid crop damages due to animals. The system has manual and automatic manner. The actual moment observed data is stored using cloud server for judgment taking and controlling measures. Consumer be able to keep an eye on controlling measures held in the farm; also have power over irrigation by the use of android application on e-farmer. 
SMART AGRICULTURE SYSTEM

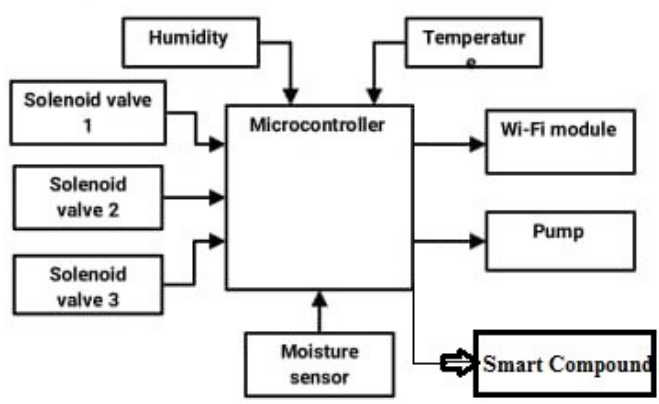

Proposed System

Figure 1: Block Diagram

The mentioned framework causes Farmer to enhance superiority and amount of their land capitulated by detecting surrounding heat and soil dampness esteem, moistness esteems \& water altitude of the storage tank from the ground level with no individual intercession. Via utilizing the idea of IOT framework can be further effective. The framework includes remote sensor put in the field to obtain the continuous qualities, an ace hub to get and transmit procured data to control segment, \& a control segment which controls the trickles for watering subsystem. Every hub incorporates temperature, stickiness, soil dampness and water altitude sensors and also microcontroller and transfer exchanging unit. The detected information from every hub is transmitted to the ace hub by means of IOT. Once the information is prepared and choice is resolved at the control area with the assistance of water system calculation, the controlling activity is sent to remote sensor hub. The microcontroller from the hub controls transfer exchanging unit and watering subsystem in like manner. Report framework that is an android application is created to convey ongoing field data to Farmer. Additionally it requests that Farmer react to a basic occurrence, for example, ascend in temperature and water necessity for plants. And compound with current pulses is also used for more farm security.

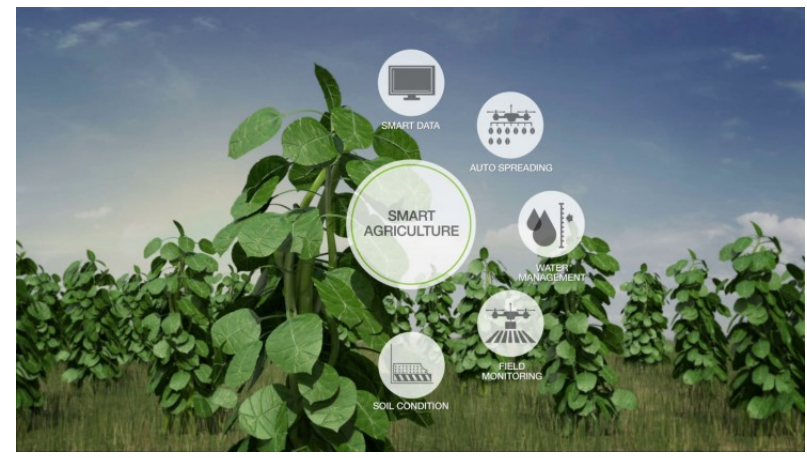

Figure 2: Proposed Structure

\section{Modules}

1) IOT:

The internet of things is a structure of interconnected computing devices, digital \&mechanical machines, objects, animals or humans that are offered with unique identifiers (UIDs) \& the capability to relocate data over a network with no requiring human-human or human-computer interaction. Also IOT is the group of physical devices, appliances embedded with electronics devices along with software operated with the help of internet which creates a great scope which results in improving efficiency, minimize human efforts and improve economy.

\section{2) Irrigation}

Irrigation is the application of controlled quantity of water to plants at required intervals. Irrigation assist's to cultivate agricultural crops, preserve landscapes, and revegetate disturbed soils in dry areas and throughout periods of a lesser amount of than average rainfall. Irrigation also encompass other uses in crop production, including frost protection, suppressing weed growth in grain fields and preventing soil consolidation. In contrast, agriculture that relies only on direct rainfall is referred to as rain-fed or dry land farming.

Advantages of Proposed System

Smart Agriculture will improve crop quality. 
Smart Agriculture will increase agricultural production.

Smart Agriculture will avoid crop damage by animals and theft of crops.

\section{Results and Discussion}

The investigation and examination identified with interrelated investigation of Internet of Things, Machine to Machine and Remote Sensor Systems, conceivable it is recognize that there are different advancements over these few years, but some issues are still remain present and need to be address regarding gathering and producing information. The framework proposed in these undertaking, plans to prompt the blend of such frameworks with the alluring highlights provided by IOT. Such joining might be connected to the agricultural applications. The mechanized water system framework exhibited within this work was discovered more feasible, and can oversee water system water supply all the more adequately. It improves the water utilization for water system reason and crop security. It demonstrates water utilization is lessened with the execution of soildampness based computerized water system framework.

\section{Conclusion}

The investigation and examination identified with interrelated investigation of Internet of Things, Machine to Machine and Remote Sensor Systems, conceivable it is recognize that there are different advancements over these few years, but some issues are still remain present and need to be address regarding gathering and producing information. The framework proposed in these undertaking, plans to prompt the blend of such frameworks with the alluring highlights provided by IOT. Such joining might be connected to the agricultural applications. The mechanized water system framework exhibited within this work was discovered more feasible, and can oversee water system water supply all the more adequately. It improves the water utilization for water system reason and crop security. It demonstrates water utilization is lessened with the execution of soildampness based computerized water system framework.

\section{References}

[1] A. Abdullah, S AEnazi and I Damaj, "AgriSys: A Smart and Ubiquitous Controlled-Environment Agriculture System”, 3rdMEC -ICBDSC, Muscat, 2016.

[2] P B Chikankar, D Mehetre and S Das, “An Automatic Irrigation System Using Zigbee In Wireless Sensor Network", ICPC, Pune, 2015.

[3] J Gutierrez, J F.Villa-Medina, A. Nieto-Garibay and M. Á. Porta- Gándara, "Automated Irrigation System Using a Wireless Sensor Network and GPRS Module", IEEE Transactions on Instrumentation and Measurement, vol. 63, no. 1, Jan. 2014.

[4] J John, V SPalaparthy, SSarik, M. S Baghini and G SKasbekar, "Design and Implementation of A Soil Moisture Wireless Sensor Network", Twenty First NCC, Mumbai, 2015.

[5] Nakutis et al., "Remote Agriculture Automation Using Wireless Link and IOT Gateway Infrastructure" 26thInternational Workshop on DEXA, Valencia, 2015.

[6] P Y Dattatraya, J Agarkhed and SPatil, "Cloud Assisted Performance Enhancement of Smart Applications in Wireless Sensor Networks", International Conference on Wireless Communications, Signal Processing and Networking, Chennai, 2016.

[7] Deepak Sharma, Amol P Bondekar, AmriteshOza, Awdhesh Kumar Shukla, C Ghanshyam, "A Technical Assessment of IOT for Indian Agriculture Sector", 47thMid-Term Symposium on Modern Information and Communication Technologies for Digital India, Chandigarh; Research Gate, April 2016.

[8] N Putjaika, S Phusae, A Chen-Im, PPhunchongharn and KAkkarajitsakul, "A Control System In AnIntelligent Farming By Using Arduino Technology”, Fifth (ICT-ISPC), Nakhon Pathom, 2016.

$30-36$ 